\title{
Discharge Criteria from PACU
}

\author{
Melanie Oakley
}

Editor-in-Chief

$\mathrm{D}$ ISCHARGE of the patient from the recovery unit is as important as admission of the patient into the unit. Each unit will have its own criteria for the time the patient will spend within the unit and this will vary depending on whether they have had a general anaesthetic or a local anaesthetic. Broadly speaking if a patient has had a general anaesthetic they will be not be discharged for at least an hour. If they have had a local anaesthetic it will be at least half an hour. Once that time has elapsed there are general criteria that the patient has to fulfill.

During the BARNA conference this year all delegates were asked if they would fill out an audit form about discharge from recovery. Because of the small response this can only be looked upon as a pilot study, but the results were interesting and worth sharing with you.

Delegates were asked a series of questions and these will form the basis for the ensuing discussion.

\section{DO YOU USE A DISCHARGE CRITERION?}

Out of the 14 people who answered this 8 said they did and 6 said they did not. This is cannot be said to be representative of the country as a whole, but gives an indication that the majority use a criteria of some sort. (Fig. 1)

\section{WHAT DISCHARGE CRITERIA DO YOU USE?}

There was a wide spread of different criteria. The majority [8] had a set of criteria encompassing the $A B C$ algorithm. This is a logical approach to discharge as this algorithm is a primary measure in post anaesthetic

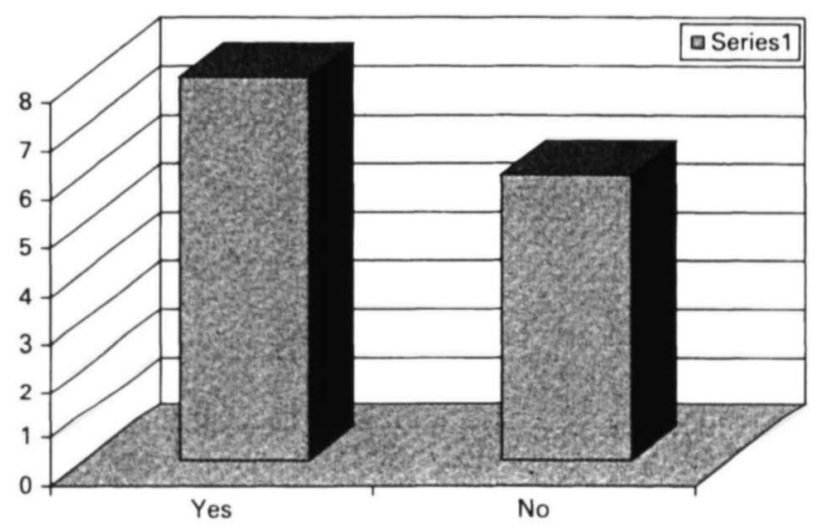

Figure 1. Do you use a discharge criterion?

patients. Other criterion used was spread evenly between the Association of Anaesthetists discharge criteria, the Glasgow coma scale and Salims coma score and discharge criteria that had been developed in house. Two of those who answered said they used an informal discharge criteria but had nothing written down. (Fig. 2)

\section{WHAT RESEARCH EVIDENCE IS YOUR DISCHARGE CRITERIA BASED UPON?}

There was a wide spread in the answers given here. The front runners were information gleaned from other hospitals, the Association of Anaesthetists and the web. Coming a close second was the Royal College of Anaesthetist and literature searches. Other sources were NATN and NICE guidelines. There was another group who based their criteria on people who have previously 


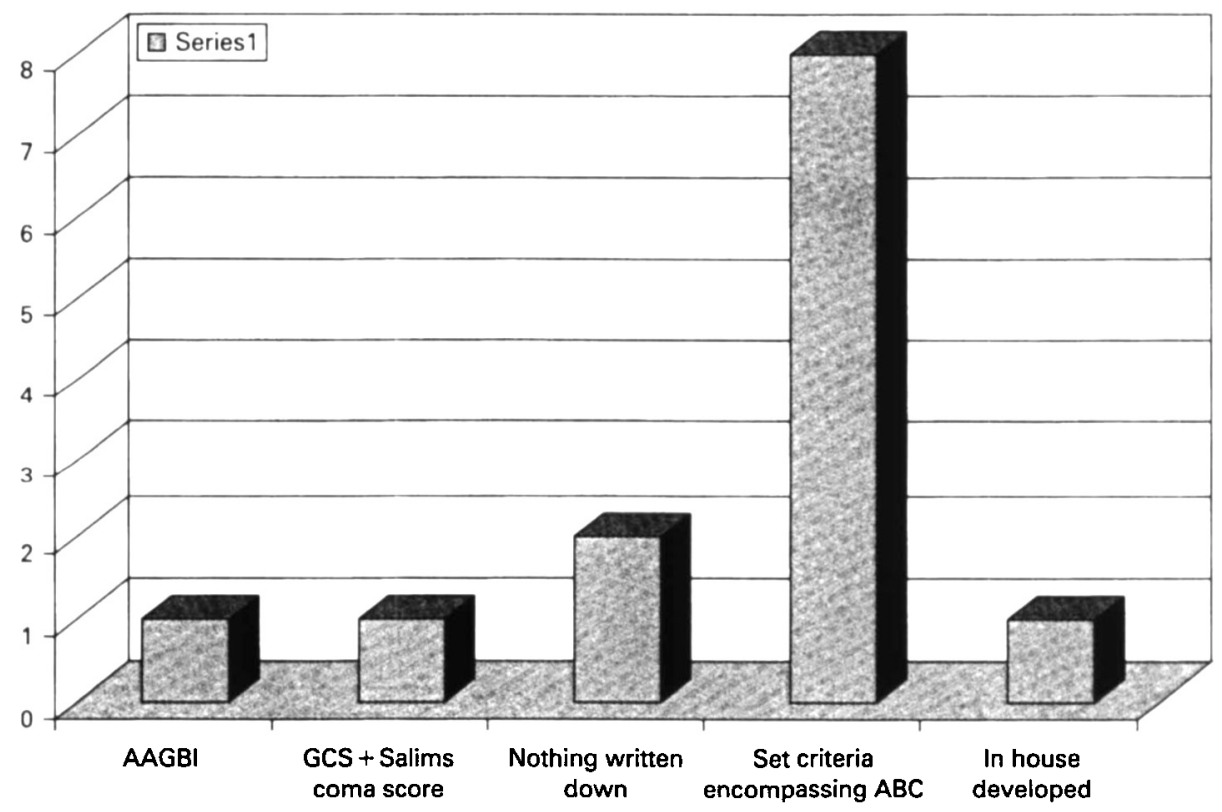

Figure 2. What discharge criteria do you use?

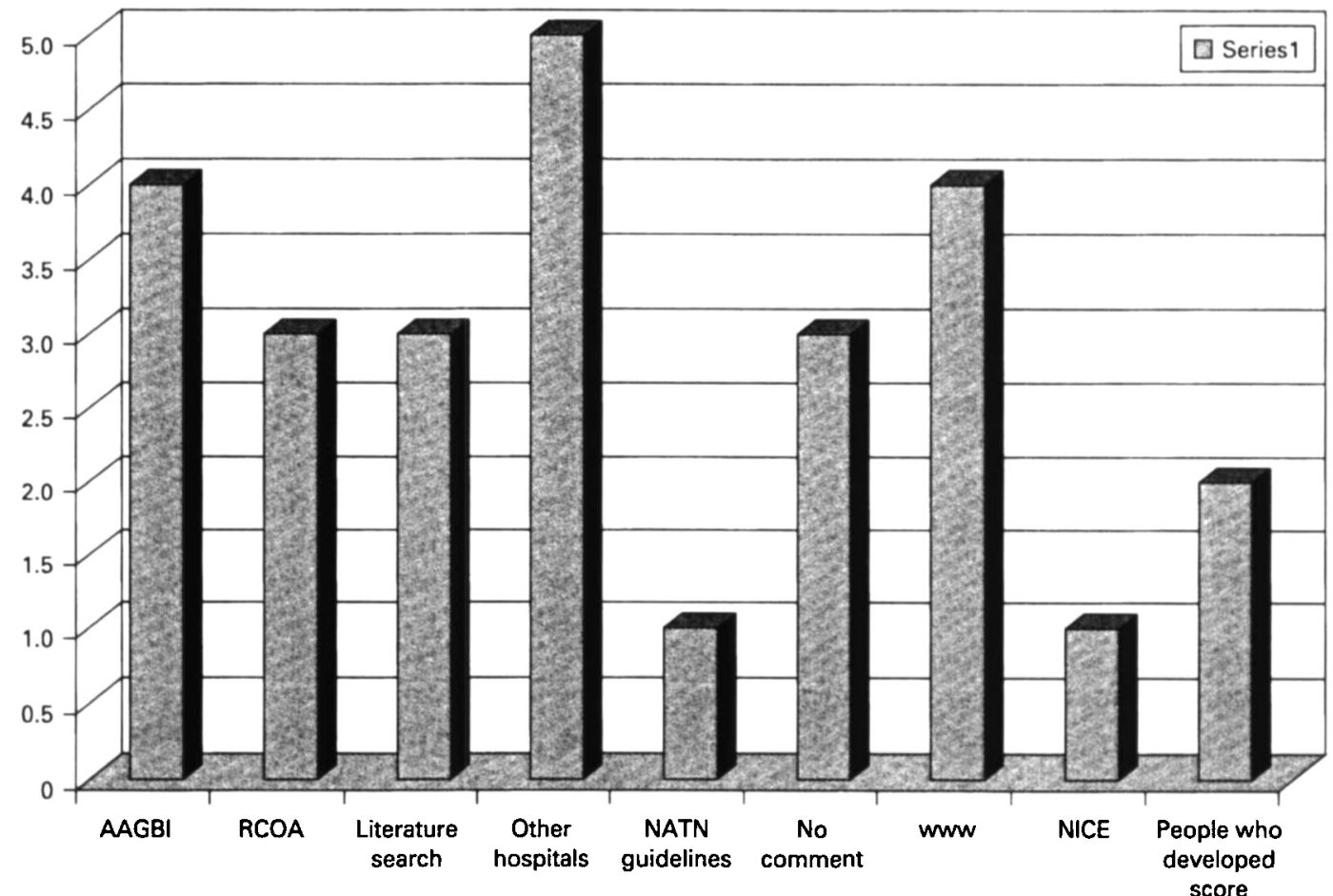

Figure 3. What research evidence is you discharge criteria based upon? 


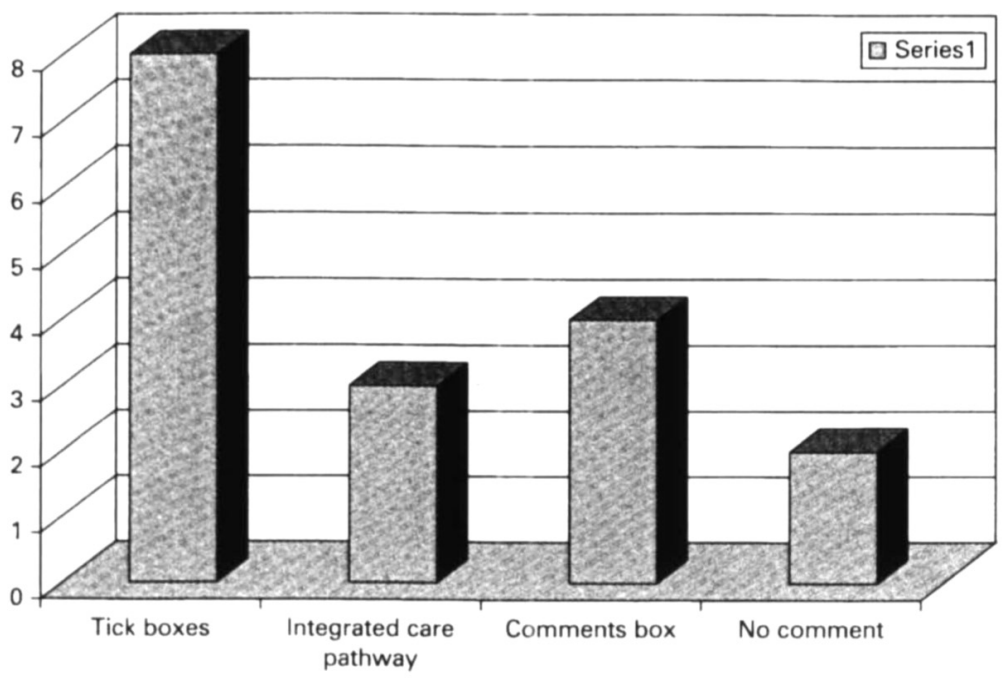

Figure 4. How do you document how discharge criteria are met?

developed a scoring system. Finally 3 people did not make any comment on this part of the questionnaire. (Fig. 3)

\section{HOW DO YOU DOCUMENT HOW DISCHARGE CRITERIA ARE MET?}

How discharge criteria are documented is very important, too complicated and people will fill it out incorrectly or not at all, and too simple and it will not give you the information you need. The majority of the sample used tick boxes. Four of the sample had comment boxes and 3 stated it was part of the integrated care pathway. (Fig. 4)

As mentioned previously, this was only a small study and can not really add anything to the body of knowledge on discharge criteria, hence why I have chosen to discuss it in the editorial. However I thought it important to share with BARNA members, and would welcome comments. I would like to hear from you if you use something different or are in the process of developing discharge criteria. Although done informally in most recovery areas I think it needs to be put on a more formal footing. 